\title{
CLINICAL COURSE OF ANAESTHESIA DURING SURGERY OF PHEOCHROMOCYTOMA
}

Sucharita Samal ${ }^{1}$, S. K. Patnaik ${ }^{2}$, N. Swain ${ }^{3}$

\section{HOW TO CITE THIS ARTICLE:}

Sucharita Samal, S. K. Patnaik, N. Swain. "Clinical Course of Anaesthesia during Surgery of Pheochromocytoma". Journal of Evolution of Medical and Dental Sciences 2015; Vol. 4, Issue 72, September 07; Page: 12618-12620, DOI: $10.14260 /$ jemds/2015/1818

ABSTRACT: The clinical course of anaesthesia during surgical resection of a pheochromocytoma of size 128 x $115 \times 92 \mathrm{~mm}$ is reported. Hypertension, hypotension, hypoglycaemia, hypovolumaeia and a single attack of convulsion were observed and managed by appropriate pharmacological intervention and fluid replacement. Both spinal and general anaesthesia were used. Recovery of the case was good.

KEYWORDS: Pheochromocytoma, spinal and general anaesthesia, Hypertension, Pharmacological intervention.

INTRODUCTION: Pheochromocytoma, the catecholamine secreting tumour, mainly arises from adrenal medulla. The incidence of this tumour is around 1.5-2.1 per million population per year.1,2 "Rute of 10 " is an important feature of this tumour as $10 \%$ are bilateral, $10 \%$ are extra-adrenal, $10 \%$ undergo malignant changes and $10 \%$ are associated with various familiar disorders. The clinical features are hypertension (65\% paroxysmal and 35\% sustained), headache, vomiting, palpitation and episodic sweating. The main organ systems involved are cardiovascular (Arrhythmias, dilated cardiomyopathy, peripheral vasoconstriction and cardiac failure), central nervous system (Anxiety psychosis and nervousness) and hypermetabolic state causing weight loss. Cardiac failure, acute pulmonary oedema, fulminant toxaemia during pregnancy and metabolic acidosis are the principal complications.

Unpredictable and fluctuating clinical features may occur during anaesthesia and surgery while dealing with this tumour. Hence, before surgical resection, the pre-operative preparation, pharmacological intervention and cardiovascular optimisation should be adequate. Adrenergic crisis occurs during induction of anaesthesia, laryngoscopy and intubation and also during tumour manipulation. To overcome this hazardous situation, adequate control of blood pressure and heart rate and correction of hypovolaemia are important.

CASE REPORT: A 32 years old female was admitted in the female Surgery Ward of I.M.S and Sum Hospital, Bhubaneswar, Odisha with the chief complaints of headache, palpitation, vomiting and paroxysmal hypertension with an abdominal swelling of 1 year duration. The CT scan of abdomen revealed a retroperitoneal cystic mass with asymmetric wall thickness of size $128 \times 115 \times 92 \mathrm{~mm}$ behind the pancreatic tail with shifting of the left kidney inferiorly and pancreatic tail anteriorly; left adrenal not seen separately from the mass and no abdominal lymphadenopathy. Laboratory parameters were VMA (Vanillylmandelic acid) 43.90mg/24 hour (Normal 1.6-7.5), serum cortisol 36.50 micro mg/dl (Normal 2.3-11) and fasting plasma sugar, serum sodium, serum potassium, serum chloride, blood urea, serum creatinine with CBC (Complete blood count) within normal range. The case was diagnosed as pheochromoytoma. Echocardiography, ECG and chest X-ray were normal. 
Pre-operatively she was treated for hypertension with different antihypertensive drugs (Telmisartan with amlodipine, prazosin and metoprolol) for 18 days. After control of blood pressure and heart rate (BP 140/98mmHg and heart rate 88 beats/minutes on the day before surgery), the patient was taken up for surgery with written consent. Preoperative check-up showed a blood pressure of $130 / 80 \mathrm{mmHg}$ and heart rate of 80 beats/minutes.

At the outset spinal anaesthesia was administered by using $3 \mathrm{ml}$ of $0.5 \%$ Bupivacaine and 180 microgram of morphine. The patient was oxygenated at a rate of $10 \mathrm{l} / \mathrm{min}$ for 3 minutes. After that the case was premedicated with $0.2 \mathrm{mg}$ Glycopyrolate, $2 \mathrm{mg}$ Midazolam and 100 microgram Fentanyl. Induction was done with $120 \mathrm{mg}$ Propofol and $6 \mathrm{mg}$ Vecuronium was used as muscle relaxant. Another $1 \mathrm{mg}, 2 \mathrm{mg}$ and $2 \mathrm{mg}$ vacuronium were administered intermittently for muscle relaxation. The case was put on BAG and MASK ventilation for about 3 minutes and 15 seconds before intubation with endotracheal tube. After intubation, the patient was shifted to ventilator mode. The volatile anaesthetic agent isoflurane was used with MAG-I and $\mathrm{N}_{2} \mathrm{O}: \mathrm{O}_{2}$ of 2:1 and maintained with IPPV.

Arterial line was placed on the left arm for continuous monitoring of blood pressure and central line catheter was placed in Right subclavian vein for monitoring of central venous pressure and drug delivery. The antihypertensive drug labetalol was administered intermittently (Total dosages were $45 \mathrm{mg}-5 \mathrm{mg}+5 \mathrm{mg}+5 \mathrm{mg}+5 \mathrm{mg}+5 \mathrm{mg}+10 \mathrm{mg}+5 \mathrm{mg}+5 \mathrm{mg}$ ) and sodium nitroprusside was used for 1 hour and 15 minutes. Phenylephrine at a dose of 50 microgram was needed once during the procedure. The other drugs used during the course of anaesthesia were $100 \mathrm{mg}$ hydrocortisone, 8 mg Dexamethasone, $1 \mathrm{mg}$ Butaphanol, $200 \mathrm{mg}$ Phenytoin Sodium and 2 litres of Ringer Lactate with $500 \mathrm{ml}$ of $5 \%$ Dextrose with normal saline. The patient was put for 24 hours in the observation room where the blood pressure and heart rate were within normal limits and thereafter she was shifted to the ward. The patient was cured and discharged after 12 days.

DISCUSSION: The present case had the clinical features of pheochromocytoma, e.g. headache, vomiting, palpitation and paroxysmal hypertension. The VMA was raised. The C.T. Scan of abdomen showed the accurate size and extension of the mass. For the first 18 days, the blood pressure was controlled adequately by the cardiologist. During anaesthesia and surgery, the blood pressure and heart rate were maintained within normal by using various antihypertensive drugs. The oxygen and fluid and electrolyte balance were maintained.

Anaesthesia and surgery of Pheochromocytoma carry a mortality rate of $50 \%$ in unprepared patients. ${ }^{3}$ However, the mortality was reduced from $13-45 \%$ to $0-3 \%$ after meticulous use of alphaadrenergic blocking drugs and well correction of hypovolemia. ${ }^{3,4}$ In the present case, we used appropriate antihypertensive drugs and volume was corrected by using fluids. We used a combined spinal and general anaesthesia as mentioned in earlier studies.5,6 The case should be closely monitored in the observation room cautiously as there is chance of hypertension, hypotension or hypoglycaemic episodes; ; though no such incidence was occurred in our case. The incidence of hypertension is $50 \%$ after resection of pheochromocytoma as elevated catecholamine levels persist for 7 to 10 days and hypoglycaemia may occur due to elevated level of insulin because of suppression of beta cells of pancreas.

CONCLUSION: Pre-operative preparation, adequate control of hypertension, hypotension and correction of hypovolemia during anaesthesia may reduce the mortality while surgically resecting pheochromocytoma. The combined spinal and general anaesthesia may be good. 


\section{REFERENCES:}

1. Manger HM, Gifford JW, Jr. Pheochromocytoma: A Clinical Overview. In: Swales JD, Editor. Textbook of Hypertension. Oxford: Blackwell Scientific: 1994, pp. 941-580.

2. Green JP, New Perceptive in Pheochromocytoma. Urol Clin North Am. 1989; 16: 487-503.

3. Desmonts JM, Le Houelleur J, Remonds P, Duvaldestin P. Anaesthestic Management of patients with pheochromocytoma. A review of 102 Cases. Br J Anaesth 1977; 49: 991-8.

4. Smith DS, Ankberg SJ, Levitt JD. Induction of anaesthesia in a patient with undiagnosed pheochromocytoma. Anaesthesiology, 1978; 49: 368-9.

5. Cousins ML, Robin RB. The intra-operative management of pheochromocytoma with total epidural sympathetic blockade. Br Jr Anaesth 1974; 46: 78-81.

6. Lee MK. Anaesthetic management for removal of Pheochromocytoma with neuroleptanaesthia using high dose fentanyl - A case report. Singapore Med J 1986; 27: 158-42.

7. Singh G, Kam P. An overview of anaesthetic issues in Pheochromocytoma. Ann Acad Med Singapore 1998; 27: 843-8.

\section{AUTHORS:}

1. Sucharita Samal

2. S. K. Patnaik

3. N. Swain

\section{PARTICULARS OF CONTRIBUTORS:}

1. Post Graduate Student, Department of Anaesthesia, IMS \& Sum Hospital, Bhubaneswar, Odisha.

2. Associate Professor, Department of Anaesthesia, IMS \& Sum Hospital, Bhubaneswar, Odisha.

3. Professor and HOD, Department of Anaesthesia, IMS \& Sum Hospital, Bhubaneswar, Odisha.

NAME ADDRESS EMAIL ID OF THE CORRESPONDING AUTHOR:

Dr. Sucharita Samal,

C/o. Dr. K. K. Samal,

Professor of Medicine, Ananta Nagar, Main Road, Berhampur-760005, Odisha.

E-mail: sucharitasamal24@gmail.com

Date of Submission: 20/08/2015. Date of Peer Review: 21/08/2015. Date of Acceptance: 01/09/2015. Date of Publishing: 07/09/2015. 